\title{
Dijital Dekorasyon Teknolojileri ile Giyilebilir Sanatta Seramik Uygulamaları
}

\section{Ceramic Applications in Wearable Art with Digital Decoration Technologies}

\section{Ceyda Sıkı}

Öğr. Gör., Uşak Üniversitesi, Deri, Tekstil ve Seramik Tasarım Uygulama ve Araştırma Merkezi

email: benceydaa@gmail.com (OORCID ID: https://orcid.org/0000-0001-5411-1417

\section{Kaan Canduran}

Prof., Hacettepe Üniversitesi, Güzel Sanatlar Fakültesi, Seramik Bölümü

email: kcanduran@gmail.com (DORCID ID: https://orcid.org/0000-0003-2170-2119

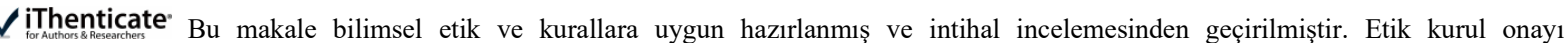
gerektirmemektedir.

Atıf (APA 7)/To cite this article

Sıkı, C., \& Canduran, K. (2021). Dijital dekorasyon teknolojileri ile giyilebilir sanatta seramik uygulamaları. Atatürk Üniversitesi Güzel Sanatlar Enstitüsü Dergisi, 27(47), 410-423. https://doi.org/10.35247/ataunigsed.962825
\end{abstract}

Makale Gönderim Tarihi/Received: $05 / 07 / 2021$

Makale Kabul Tarihi/Accepted: 08/09/2021

Makale Yayın Tarihi/Published: 28/10/2021

Research Article / Araștırma Makalesi

\section{Öz}

Tarih öncesinden günümüze dek seramik, bulunduğu dönemin ihtiyaçlarını karșılamasından kullanıcısına duygu ve düşüncelerini yansıtmasına kadar teknik ve teknolojik imkanlar doğrultusunda vazgeçilmezliğini koruyarak gelişme göstermiștir. Kilin kendine özgü yapısı, sanatsal alanda farklı yönelimde disiplinler arası bir yaklaşım ile giyilebilir sanat (wearable art) alanında alternatif bir malzeme olarak yeni biçim önerileri sunmaktadir.

Bu araştırmada, giyilebilir sanat kavramına ve bu kavram ile ilgili seramik malzeme ile çalışmalar yapan sanatçı çalışmalarından örneklere yer verilmektedir. Giyilebilir sanata yönelik çalışılan sırsız pişmiş seramik formların üzerine sayısal ortamda geliştirilen desenlerin, dijital dekorasyon teknolojileri $\left(\mathrm{CO}_{2}\right.$ gaz lazer ve inkjet teknolojileri) ile yüzey üzerine işlenerek dekor oluşturulması süreci açıklanacaktır. Uygulamalar drapaj tekniği ile ortaya çıkarılan giysiler üzerine yerleştirilen özgün seramik formlar ile gerçekleştirilmiştir. Yapılan çalışmada, dijital dekorasyon teknolojilerinin uygulamada kullanılması sonucu ortaya çıkan bilgi ve tecrübenin paylaşılması ile konu özelinde araştırmacılara yeni ufuklar açıp ilham verici olması hedeflenmiştir.

Anahtar kelimeler: Giyilebilir Sanat, Seramik, Dijital Dekorasyon Teknolojileri, İnkjet, Lazer

\begin{abstract}
From prehistory to the present, ceramic has developed by preserving its indispensability in line with technical and technological possibilities, from meeting the needs of its period to reflecting the feelings and thoughts of its users. The unique structure of the clay offers new form suggestions as an alternative material in the field of wearable art with an interdisciplinary approach with a different orientation in the artistic field.

In this research, the concept of wearable art and examples of works by artists working with ceramic materials related to this concept are included. The process of creating decor by processing digital decoration technologies $\left(\mathrm{CO}_{2}\right.$ gas laser and inkjet technologies) on the unglazed fired ceramic forms studied for wearable art on the surface will be explained. The applications were carried out with original ceramic forms placed on the clothes revealed by the draping technique. The study aims to open new horizons and inspire researchers by sharing the knowledge and experience that emerged as a result of the use of digital decoration technologies in practice.
\end{abstract}

Keywords: Wearable Art, Ceramic, Digital Decoration Technologies, Inkjet, Laser

\section{Giriş}

Sanat ve tasarım, teknoloji ve bilim alanları ile birbirlerini üst platforma taşıyan bir dinamizm içerisinde gelişme göstermektedir. Teknolojik araç ve gereç zenginlikleri, sanatçı ve tasarımcılar için bir tür araştırma ve uygulama alanları oluşturmaktadır. Tasarımların yaratılmasında olasılıkları arttıran etkinlikler ile deneyimler malzeme ve üretim sürecine yeni bir yaklaşım getirdiği bir gerçektir. Teknolojik yöntemler, süreç içerisinde farklı fikirlerin farklı disiplinlerde harmanlama özelliğini doğurmuştur.

Teknolojinin getirdiği disiplinler arası yaklaşım, sanatçı için düşünsel ve biçimsel açıdan sınırsız bir özgürlük alanı sunmaktadır. Yüzeysel ve üç boyutlu kullanım olanaklarının yanı sıra kendine özgü süreçleri ve üretme teknikleri ile seramik, modern sanata öncelikli malzeme olarak girmiştir (Karayel Gökkaya, 2014, s. 26). Özellikle bilgisayar teknolojisi başta olmak üzere yeni teknolojilerin tasarım, üretim, sergilemede yöntem ve süreçlerine dahil edilmesiyle günümüzde kullanımları yaygınlık kazanmıştır. Seramik alanında da her geçen gün dekorasyon sürecinde modernizasyonu görülmekte olup özgün seramik yüzey tasarımı uygulamalarına olanak verilmektedir.

Seramik endüstri alanında dijital dekorasyon teknolojileri olarak inkjet baskı sistemleri ile lazer ile dekorlama yaygın olarak kullanılmaktadır. İnkjet teknolojisinde, baskı kafalarının belli bir yüksekliğe kadar çıkabilmesi nedeniyle; 2 boyutlu ve rölyefli yüzeylerde kullanılabilmesi mümkün kılınmaktadır. Söz konusu makale 
çalışmasında ise, bu teknolojilerin seramik malzeme üzerinde kullanılarak formların 3 boyutlu hale getirilmesiyle, giyilebilir sanata yönelik olan özgün bir deneysel çalışma yapılması hedeflenmiştir.

Çalışma kapsamında; ilk olarak çalışmanın odaklandığı giyilebilir sanat ve seramik malzeme ile giyilebilir sanat örnekleri incelenmektedir. İnsanlık tarihi kadar köklü bir geçmişe sahip olan seramik, çok farklı alanlarda kullanım bularak üretildiği dönemin kültürü, sosyolojisi ve ekonomisi gibi birçok önemli bilgiler taşımaktadır. Geçmiş uygarlıklara 1şık tutan seramik, üzerindeki bezemeler ile dönemin giyimini de yansıtmaktadır. Seramik yüzeylerindeki bezemeler ile sikkeler bu çalışma için esin kaynağı olarak belirlenmiştir. Bu doğrultuda ikinci adımda ise, çalışmanın tasarımdan üretim ve sergileme sürecine kadar esin kaynağı doğrultusunda insan anatomisine yönelik el ile şekillendirilen seramik formlar ve bu formlar için çalışılan yüzey tasarımlarına değinilmektedir. Tekstil malzemeler aracılığı ile seramik formlarla bir arada kullanılarak giyilebilir sanat örneğinde koleksiyon oluşturma süreci açıklanmaktadır.

\section{Yöntem}

$\mathrm{Bu}$ çalışma, giyilebilir sanat kavramı ve giyilebilir sanatta seramik malzemenin yeri incelenmiş olup literatür taramasının yanı sıra internet ortamındaki doküman analizi yöntemi ile bütüncül bir şekilde veri toplanarak oluşturulan nitel bir araştırmadır. Araştırma kapsamında, bilimsel modele dayalı olarak sanatçı çalışmaları örnekleri ile verilerin içerik analizi gerçekleştirilmiştir. Analizlerin yorumlanarak değerlendirilmesi ile dijital dekorasyon teknolojileri ile yenilikçi sanatsal uygulamalar yapılmıştır. Bulgular ilişkilendirilerek yapılan değerlendirilmeler sonuç bölümünde açıklanmıştır.

\section{Bulgular}

\subsection{Giyilebilir Sanat}

Giyinme kavramı, bireylerin kendilerini ifade edebilmek adına bedenleri doğrultusunda görsel bir anlatım olarak kurguladıkları yorum ile örtünmeden ayrılmaktadır (Atik, 2019, s. 38). Çevresel koşullardan korunma anlamı taşıyan giysi kavramı, tarihsel süreç içerisinde her gün yeni bir anlam yüklenerek bir mesleğin, toplumsal bir statünün, siyasi bir bakış açısının ya da kişisel bir duruşun biçimsel simgesi olarak sosyoloji, ekonomi ve tarihin ilgi alanı içinde olarak önemli bir yer bulmuştur (Pamuk, 2020, s. 5345).

Giysiyi tasarlayan sanatçı hislerini, duygu ve düşüncelerini, kültürel izlerini yorumu ile giysiye aktarmakta olup, giysi de Sanat ve Zanaat hareketinin etkisi ile 1980'lerde giyilebilir sanat (Wearable Art, Art to Wear, Artwear) ile anılmaya başlamıştır (Ok, 2016, s. 72). "Wearables" kelimesi İngilizcede giymek= onu vücudunda taşımak fiilinden gelmektedir. Bu nedenle "Wearables" giyebildiğimiz ya da üzerimizde taşıyabildiğimiz (örneğin kıyafetler, aksesuarlar, ayakkabılar, gözlükler, medikal cihazlar vb.) birçok unsuru kapsayan jenerik bir kelimedir (Paret ve Crégo, 2019, s. 5). Sanat ve Zanaat hareketi, (Arts \& Crafts) ters ve suistimale dayanan endüstriyel sistemin temellerini düzeltme amacını taşımakta olup sanat-zanaat ayrımını ortadan kaldırarak, el emeğini ve özgün yaratıcılığı yüceltmiş̧tir (Özay, 2021, s. 25). Arts and Crafts Akımı: "19. Yüzyılın ikinci yarısında gelişen bir İngiliz sanat akımı" olarak tanımlanmaktadır (Sözen ve Tanyeli, 2012, s. 35). Bu akımın oluşturduğu disiplinler arası alanda sanat ve modanın birlikte ilerlediği görülmektedir (Atik, 2019, s. 34). Giysi ile derinlemesine bağlantılı olan moda kavramının kelime anlamına bakıldığında ilk olarak "Değişiklik gereksinimi veya süslenme özentisiyle toplum yaşamına giren geçici yenilik" olarak tanımlanmaktadır (Türk Dil Kurumu, t.y.). Demiray (1988) ise, "Temel Türkçe Sözlük" kitabında moda kelimesini "zamanın zevkine göre ortaya çıan geçici yenilik. [...]" olarak belirtmiştir (s. 627). Moda tasarımının ve tekstilin bir alt dalı olan giyilebilir sanat, vücudun bir araç olarak kullanılarak, imge ve düşüncelerin belirli formlara dönüştürülmesinde bir ifade biçimi şeklinde tanımlanmıştır (Kodaman ve Sarı, 2013, s. 78).

Yeni bir gelişme olarak bilinen ve giderek benimsenen estetik değerler ile oluşturulan giyilebilir sanat, dünya çapında yarışmalarda konu olmuştur. Örneğin Yeni Zelanda'nın Wellington şehrinde 30 yılı aşkın bir süredir düzenlenmekte olan "Giyilebilir Sanat Ödülleri, World of Wearable Art (WOW)", her yıl farklı temalar belirlemekte olup yaklaşı 60.000 kişi izleyici kitlesine sahip dünyanın önde gelen uluslararası giyilebilir sanat yarışma platformu sunmaktadır (Görsel 1).

İçinde bulunduğumuz yüzyılda ise teknolojik gelişmeler; araştırma, tasarım geliştirme, üretim ve sergileme portföy süreçlerinde dijitalleşme fırsatı sunmaktadır. Dijital üretim ile baskı teknikleri hız kazanarak stil ve görsellik oluşmasında etkin rol oynamaktadır. Bu gelişmelerin en önemli getirilerinden birisi ise dijital baskı teknolojileridir. Bu dijital baskı teknolojilerinden inkjet baskı kullanarak tekstil alanında yenilikçi çalışma yapan sanatçılardan birisi de Mary Katrantzou'dur (Görsel 2). 
Görsel 1

Kirsten Fletcher, 'Woven In-tent' 2019 Supreme WOW İkincilik Ödülü

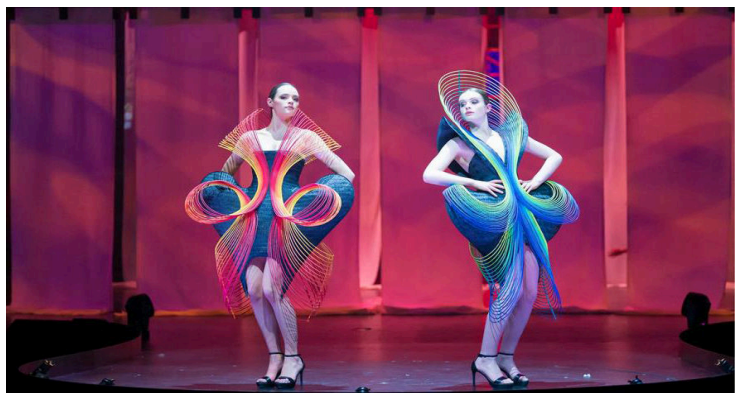

(Brix, 2019)

Görsel 2

Mary Katrantzou, 2012 İlkbahar Yaz Koleksiyonu
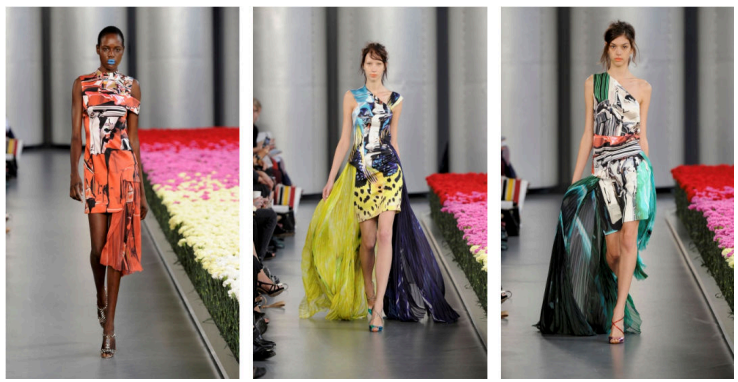

(Katrantzou, 2012)

Geliştirilen bu baskı teknolojileri sadece tekstil alanında değil seramik, deri, ahşap vb. multidisiplinler alanlarda da görsel araştırma ile tasarım stil ve yönlerinin geliştirilerek kullanımı her geçen gün yaygınlaşmaktadır. Teknoloji gelişmeye devam ettikçe her alanın kendi içerisine uygun mürekkep, pigmentler ve materyaller iyileştirilerek seri üretime olanak vermektedir.

\subsection{Giyilebilir Sanat Örneğinde Seramik}

Giyilebilir sanat eserleri, performans sanatı, vücut sanatı ve diğer benzeri sanatlar ile yakın ilişki içerisinde olarak, sanatçı isteği doğrultusunda tekstil dışı ahşap, cam, saç, seramik, taş gibi malzemeler kullanılarak beden üzerinde sanatsal bir form oluşturulabilir (Arabalı Koşar ve Kurtuldu, 2017, s. 31-35). Seramik, metal, tel, atık malzemeler vb. gibi malzemelerden yapılan çalışmalar farklı disiplinlere ait ortak fikirler üretme konusunda moda tasarımında yaratıcı ifadelere olanak sağlamaktadır (Hakan Verdu Martinez, 2012, s. 162). Giysi tasarımı aşamasında teknik ve teknolojinin yanı sıra estetik ve sanatsal unsurlara da ihtiyaç vardır (Geyik Değerli, 2019, s. 52). Günümüzde teknolojik yenilikler doğrultusunda her alan kendi içerisinde birbirinden etkilenmekte ve gelişme göstermektedir. Bu doğrultuda tekstil ve seramik yüzeyleri arasındaki ilişki her geçen gün sınırları belirsizleşerek birbirlerinden etkilenmektedir. Dolce \& Gabbana, deniz renkleri ve 1960'ların mimarisi olan el yapımı geometrik desenler ile ilişkilenmiş olup tekstil yüzey tasarım ve seramik yüzey tasarımı arasında bir bağ kurarak erkekler ilkbahar-yaz 2021 koleksiyonu oluşturmuştur (Görsel 3).

Görsel 3

Dolce \& Gabbana İlkbahar-Yaz 2021 Erkek Koleksiyonu

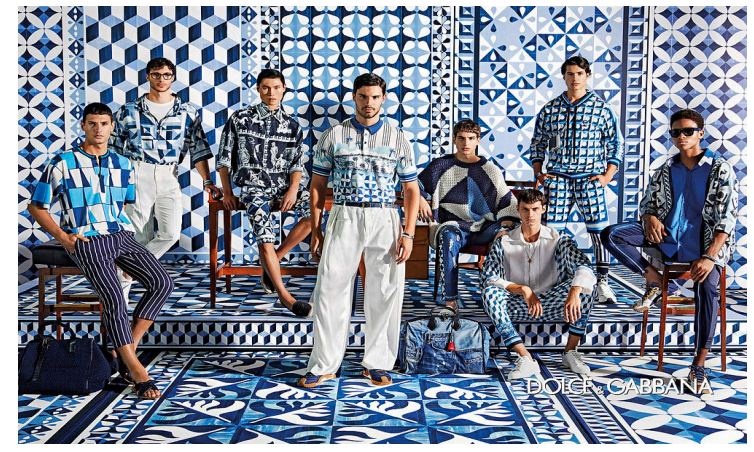

(Dolce\&Gabbana, t.y.). 
Zanaat olarak görülmesinin yanı sıra sınıf farklılıklarını, ekonomik seviyeyi ve statüyü yansıtan takılar, yeni çağın gelişen ve yenilenen teknolojisi ile farklı anlamlara bürünerek sanat alanında kendine yer edinmiştir. Sanatsal anlamda tasarlanmış olan takılar giyilebilir sanat kavramı içerisinde incelenmektedir. Sanat eseri olarak değerlendirilmesi takılara olan bakış açısını değiştirmiş olup bir ifade aracı olarak insan bedeni ile birlikteliği sayesinde farklı bir boyut kazanarak giyilebilir sanat kavramı içerisinde yer almaktadır (Yeşilmen, 2018, s. 1252).

Seramik malzeme kullanarak çağdaş takı tasarımı yapan sanatçı Ezster İmre seramik tabaklardan koleksiyon geliştirmiş olup farklı bir anlatım yakalayarak tasarımlarını bu yönde geliştirmiştir (Görsel 4).

\section{Görsel 4}

Eszter Imre Vivienne Bella
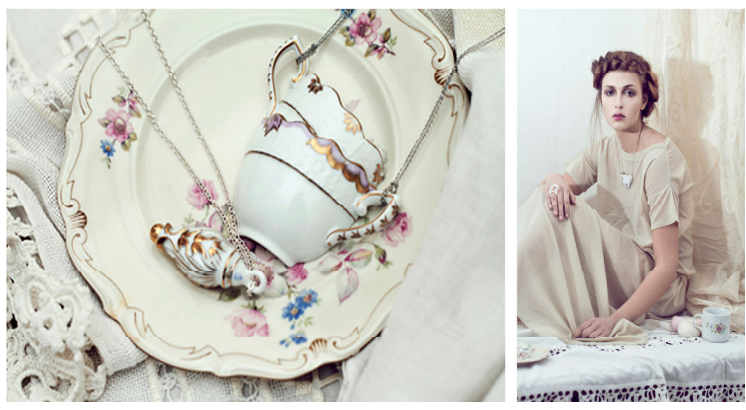

(Bella, t.y.)

Bir nesne olarak bedeni ele alarak seramik ile çalışan bir diğer sanatçı da Phoebe Scott yeni tasarımların ortaya çıkmasında ilham kaynağı olmuştur (Görsel 5).

\section{Görsel 5}

Phoebe Scott, Seramik Çalışması
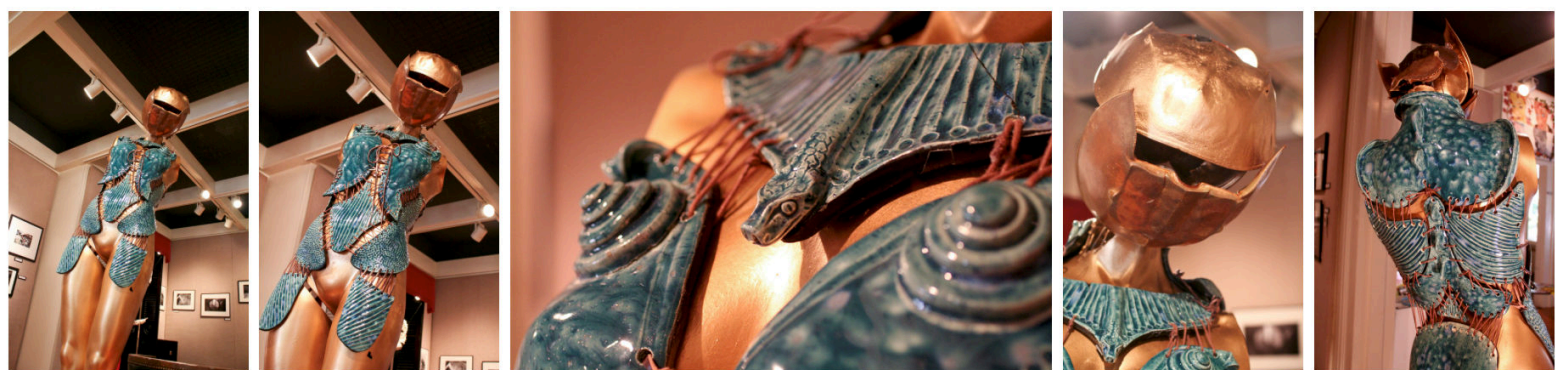

(Scott, t.y.)

Antik kazı alanlarından topladığı mavi-beyaz porselen parçaları yeni yüzyıla moda ögeleri olarak katarak tanınan Li Xiaofeng, porselen malzeme ile heykelsi giyilebilir kostümler oluşturmaktadır. Porselen parçalarını ince metal tel kullanarak birbirine dikerek desenlerdeki renklerin yeni tonlar oluşturması ile yeni bir anlatım dili sağlamaktadır (Görsel 6).

\section{Görsel 6}

Li Xiaofeng, Porselen Malzeme ile Kostüm
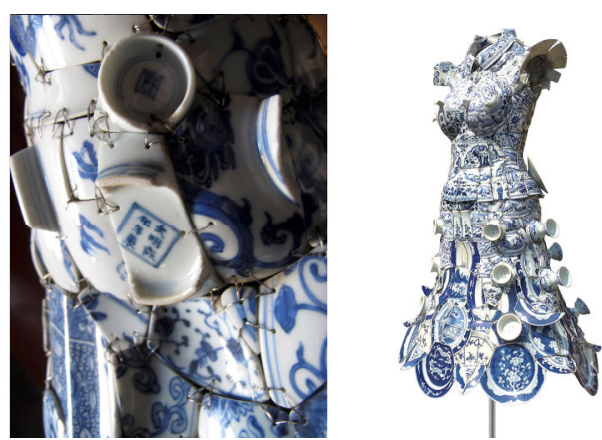

(Xiaofeng, t.y.)

Yine aynı şekilde seramik malzeme ile giyilebilir çalışmalar yapan sanatçılar Malou van der Molen ve Marie Pendariès seramik alanına yeni bakış açısı sunarak ilham kaynağı olmaktadır (Görsel 7-8). 


\section{Görsel 7}

Malou van der Molen Seramik Elbise Çalışması

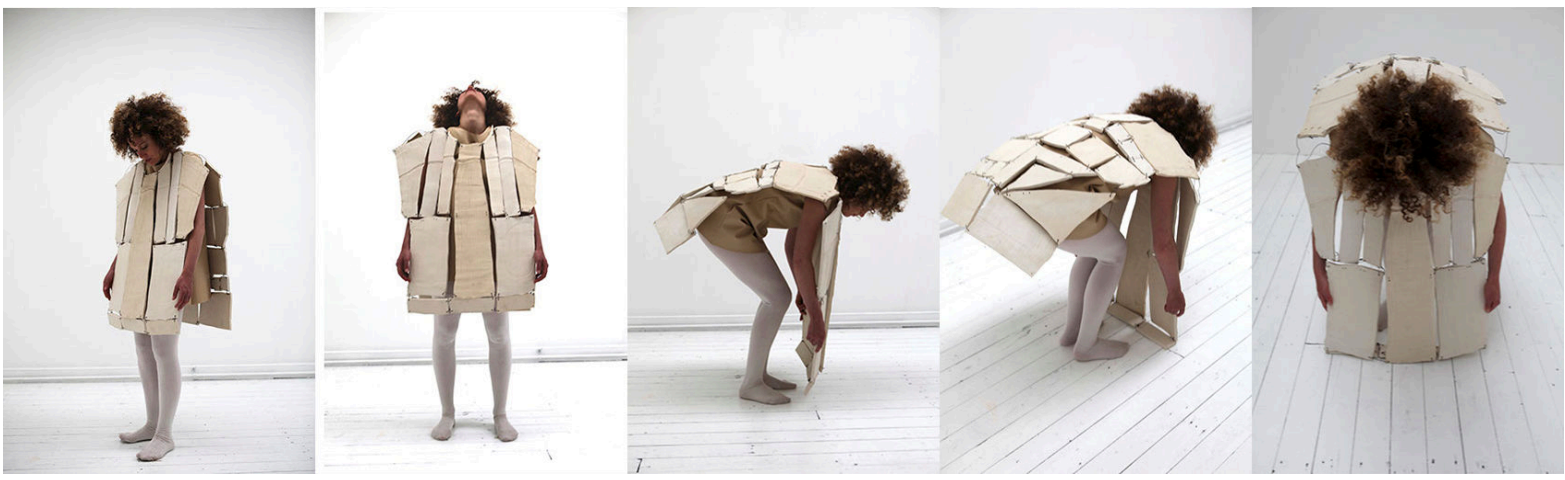

(Van der Molen, t.y.)

\section{Görsel 8}

Marie Pendaries, La Dot

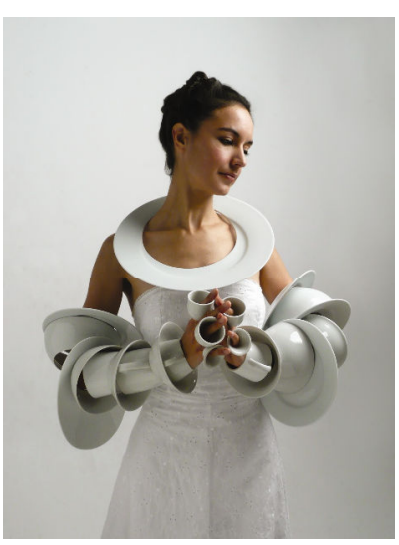

(Pendaries, t.y.)

Ezgi Hakan Martinez, beş farklı renkte yaklaşı 1700 adet seramik lale formu ile Fatih Sultan Mehmet'in sarayının bahçesinde yetiştirdiği laleleri anımsatmakta olan kaftan tasarımı ile seramik malzeme ile giyilebilir sanata biçimsel olarak ve estetik açıdan farklı bakış açısı kazandırmıştır (Görsel 9).

\section{Görsel 9}

Ezgi Hakan Verdu Martinez, Kaftan ve Detayl.
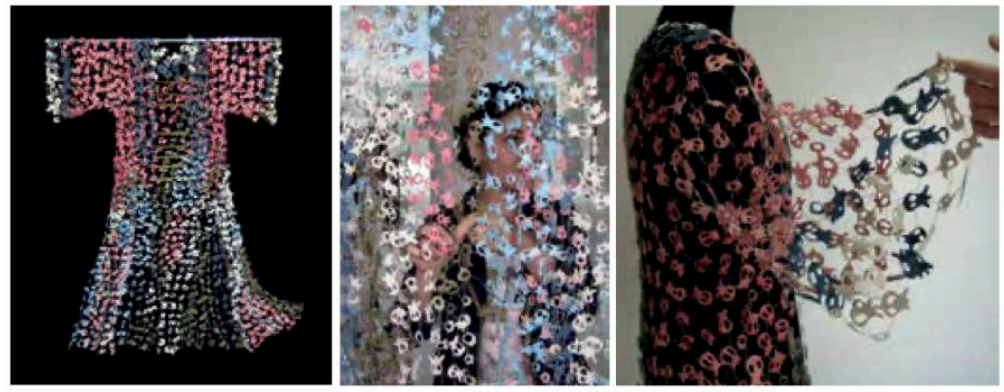

(Hakan Verdu Martinez, 2012, s. 179)

\subsection{Seramik Endüstrisinde Dijital Dekorasyon Teknolojileri}

Dijital dekorasyon teknolojileri, bilgisayar destekli tasarım programlarının dekorasyon sürecine dahil edilmesi ile başlamaktadır. Dijital dekorasyon teknolojileri; sayısal ortama aktarılmış ya da sayısal ortamda oluşturulmuş çizimlerin grafik işleme yazılımları ile görüntülerin dijitalleştirilerek uygulamaya hazır hale getirilmesi odaklıdır. Bilgisayar teknolojilerinin ve bununla beraber bilgisayar yazılım, donanım ve programlarının çeşitliliği yeni tasarımların gerçekleşmesine olanak sağlamaktadır. Bu programlar sayesinde bilgisayar ortamında oluşturulan görüntüler dijital üretim teknolojileri ile birleşerek kolayca üretime geçirilmektedir. 
Seramik endüstrisinde dekorlama aşamasında yaygın olarak kullanılan dijital dekorasyon teknolojilerin başında inkjet baskı teknolojileri ile lazer ışını ile 1sıl işlem olarak dekorlama gelmektedir.

Dijital baskı yöntemlerinden biri olarak inkjet, mürekkep püskürtmeli teknoloji olarak, bilgisayar kontrolü altında bir baskı kafasından çıkan sıvı damlacıklarının alt tabakaya yönlendirilerek hızlı bir yazma veya yazdırma işlemidir (Hudd, 2010, s. 5). Birçok farklı işlem modunu barındıran inkjet teknolojisi sürekli (Continuous) mürekkep püskürtmeli ve Kontrollü Damlacık Oluşumu (Drop on Demand) olarak iki ana sınıfa ayrılmaktadır (Gençkaya, 2011, s. 13-16).

İnkjet makinasına bağlı olan bilgisayarların uygun yazılım ve donanıma sahip olması gerekmektedir. Üretimde baskı miktarları kullanıcı talebi doğrultusunda ayarlanabilmektedir. Seramik işletmelerinde temassız işlem yapılması sayesinde maliyete olumlu katkısı tercih sebepleri arasındadır. Geleneksel baskı yöntemlerinden serigrafi ve tambur elek baskılara kıyasla üretim akışını kesmeden test baskılar yapılabildiği için durma süresini azaltır. Karo yüzeyine uygulanacak grafiklerin RGB, CMYK ya da Multichannel (çoklu kanal) uzantılı olarak çalışılması gerekmektedir.

Seramik endüstrisinde dekorlamaya yönelik kullanılan lazer teknolojisi ile karbondioksit gaz lazerlerdir.

Lazer, "Uyarılmış Radyasyon Yayınlanması Yoluyla Işı̆̆ın Kuvvetlendirilmesi” anlamına gelen İngilizce LaserLight Amplification by Stimulated Emission of Radiation kelimesinin baş harflerinden oluşan bir kisaltmadır (Arcan, 2011, s. 1). Lazer, temelleri 20. Yüzyılın başlarında Albert Einstein ile atılmış olup, 1960'lı yılların başlarında uygulamaya başlatılmıştır. İcat edildiği günden beri endüstri, sanayi, askeri, sağlık, bilim gibi alanlarda birçok çalışmaya hız kazandıran nitelikte ve aynı zamanda çok önemli bilimsel araştırma cihazlarıdır.

Lazer aktif maddelerin uyarılması ile lazer ışını elde edilir. Lazer ışınları, enerjisi güçlü olup yüksek genlikli, tek renkli, uzaklaştıkça dağılmayan ve yön verilebilen, oldukça yoğun ve aynı fazlı gibi karakteristik özellikleri ile diğer 1şık kaynaklarının yaydığı 1şıklardan farklılık gösterirler. Lazer aktif maddelerin uyarılması ile lazer 1şını elde edilir. Lazerler, aktif maddeye bağlı olarak gaz lazerler, katı hal lazerler, yarı iletken diyot lazerler ve boya lazerler olarak sınıflandırılmaktadır (Tarakçığlu ve Özcan, 2004, s. 16-29).

Direkt olarak lazer makinası altında işlem yapılmamış çalışmaların, lazer baskı olarak anılması yanlıştır. Örneğin bir dekal kâğıt üzerine fotokopi ya da yazıcı aracılığı ile desenin işlenmesi ve daha sonra bu görüntülerin yüzeye aktarılması ile lazer baskı olarak adlandırılması literatürde bilgi kirliliği yaratmaktadır.

\section{4. $\mathrm{CO}_{2}$ Gaz Lazer ve İnkjet Dekorasyon Teknolojileri ile Seramik Uygulamaları}

İnsanoğlunun dünya üzerinde bıraktığı 2,5 milyon yıllık kültürel tarihinde binlerce yıl öncesini günümüz ile buluşturan arkeoloji, zamana derinlik kazandırarak uygarlığın gelişim sürecine tanıklık sağlamaktadır. Özdoğan (2014) "50 Soruda Arkeoloji”" kitabında arkeolojiyi; "Geçmiş dönemlerde yaşamış insan topluluklarının kültürel ve toplumsal düzenlerini, günümüze kadar gelebilen maddi kalıntılara dayanarak araştıran, belgeleyen ve gelişim sürecini inceleyerek yorumlamaya çalışan bir bilim dalıdır" olarak betimlemektedir (s. 19). Günümüzde arkeolojik buluntular tarih öncesi zamanlardan itibaren kültür durumu ve gelişimi hakkında bilgi sağlamaktadır (Görsel 1011-12).

\section{Görsel 10}

Boeotian Pişmiş Toprak Heykelciği, M.Ö. 8. yy

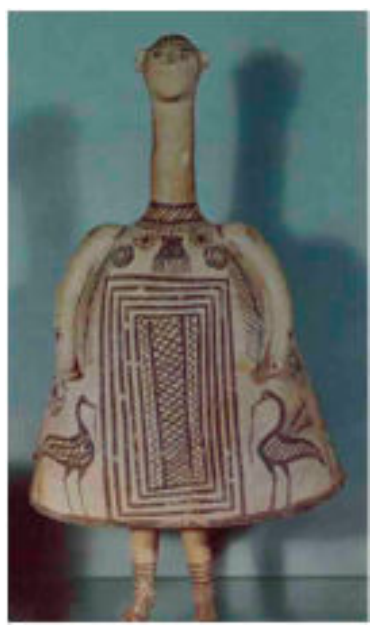

(Boucher, 1987, s. 23) 


\section{Görsel 11}

The Tiara Goddess, Knossos'tan Polikrome Terracotta Figurine, Geç Minoan

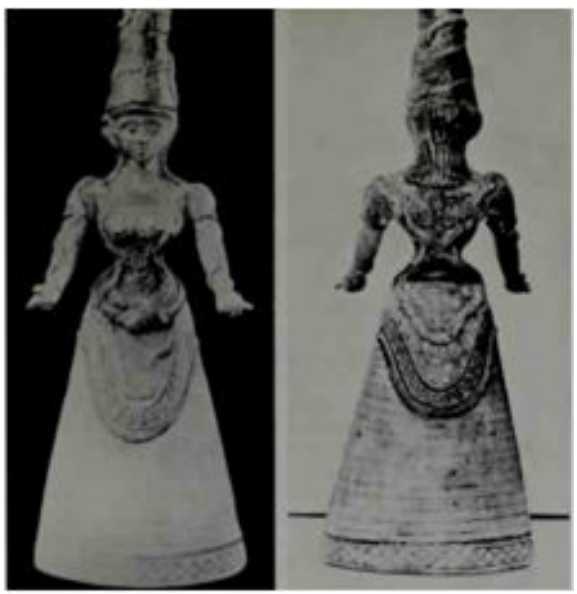

(Boucher, 1987, s. 79)

\section{Görsel 12}

Yılan Tanrıça, Knossos'tan Çok Renkli Pişmiş Toprak Heykelcik, Geç Minoan

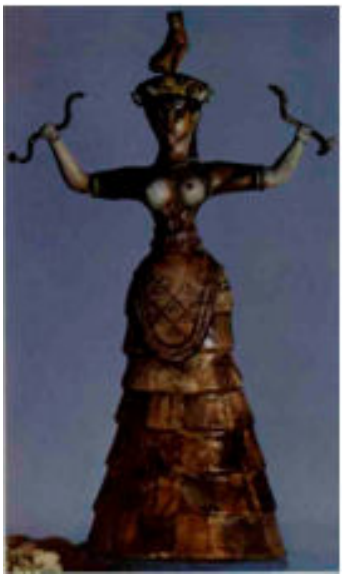

(Boucher, 1987, s. 81)

Pişmiş toprak olarak ifade edilen ve ana malzemesi kil olan seramik, doğa koşullarına dayanıklı bir malzeme olarak kolay ulaşılabilir ve şekillendirilebilir olması ile insanlık tarihine paralel bir gelişim göstererek uygarlığın oluşmasında önemli bir etken olmuştur. Şekillendirilmeye başlandığı andan itibaren gerek şekil ve biçim ile gerekse yüzeydeki bezemeleri ile ait olduğu dönemin sosyal yapısı, kültürü, gelenek ve görenek gibi ögeleri yansitan özelliği ile bilinmektedir.

Bu araştırma kapsamında, fikir ve kavram olarak tasarım aşamasında, arkeoloji dünyasına kazandırılmış Antik Yunan Dönemi, Roma Dönemi (İ.Ö. 30- İ.D. 395) ile Hellenistik Dönem olarak kendine özgü stillerinde ürettikleri çanak-çömlek bezeme desenleri ile sikkeler belirlenmiştir. Hellenistik dönem, arkeolojide genel olarak, Büyük İskender'in İÖ. 334'te Anadolu'ya geçişi ile İÖ. 30. yılları arasındaki 300 yıllık süreç olarak tanımlanır (Bingöl, 2009, s. 2). Türk Tarih Kurumu (1989), sikke kavramını; “Ticarette ve günlük alışverişlerde ödeme aracı olarak kullanılan, ağırlığı ve içindeki değerli maden miktarı devlet tarafından üzerine konan resim ve yazılarla garanti altına alınmış, belirli bir şekli olan madeni bir parçadır" olarak tanımlamıştır (s. 37).

Uygulama aşamasında ise insan vücudu ve anatomisi doğrultusunda seramik malzeme ile giysi tamamlayıcıları olan kemer, sutyen, korse vb. giyilebilir seramik form çalışmaları yapılmıştır. Tekstil malzemelere yakın görünüm kazandırılması amacı ile bazı yüzeylerde kumaş basılarak rölyefli bir görüntü elde edilmiştir. $1000\left({ }^{\circ} \mathrm{C}\right)$ derecede pişirim yapılmıştır (Görsel 13). Yine aynı şekilde yaklaşık 300 adet sikke formları el ile şekillendirilmiş olup 1000 $\left({ }^{\circ} \mathrm{C}\right)$ derecede pişirim yapılmıştır (Görsel 14). 


\section{Görsel 13}

$\mathrm{CO}_{2}$ Gaz Lazer Baskı Için Seramik Sikke Form Şekillendirme, $1000{ }^{\circ} \mathrm{C}$ 'de Pişirim, 2021

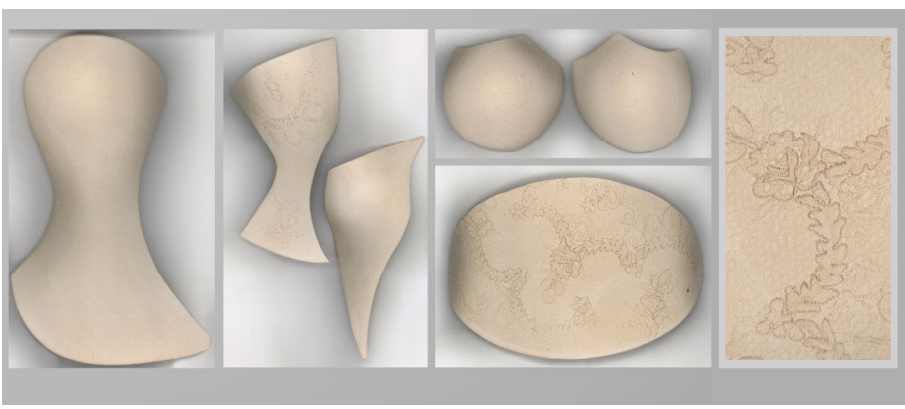

(S1k1, 2021)

\section{Görsel 14}

Inkjet Baskı Iç̧in Seramik Sikke Form Şekillendirme, $1000{ }^{\circ}$ C’de Pişirim, 2021

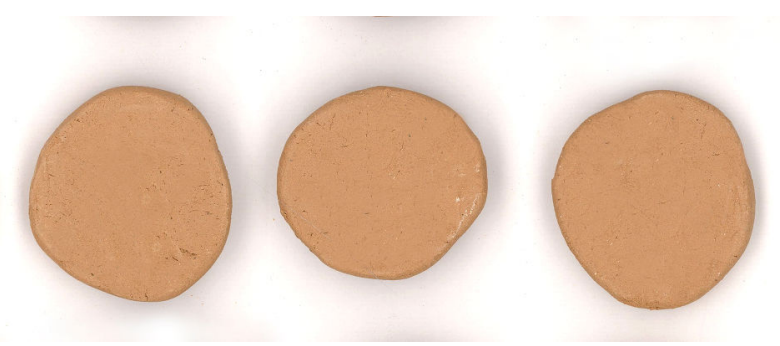

(S1k1, 2021)

Arkeolojik buluntulardaki kişisel tercih doğrultusunda belirlenen desenler, yeniden yorumlanarak teknoloji olanağı ile yeni anlatımlara dönüştürülmesi üzerine çalışılmıştır. Kavram araştırmasında temanın renk paleti, arkeolojik buluntulardaki bezemelerden yola çıkılarak hazırlanmıştır (Görsel 15-16-17).

\section{Görsel 15}

Kırmızı Figürlü Kylix C, M.Ö. 470 Python'a (çömlekçi), Douris'e (ressam) Atıf, Geç Arkaik

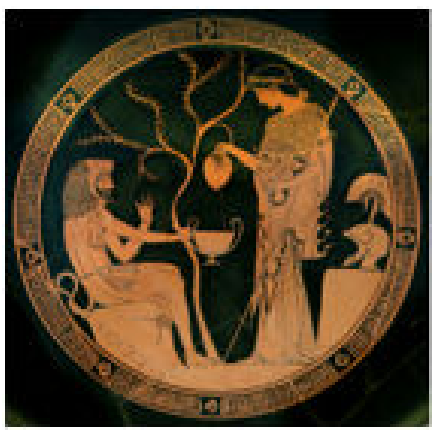

(Sani, 2010)

\section{Görsel 16}

Kanatlı Deniz Atı Broşu, Uşak Müzesi

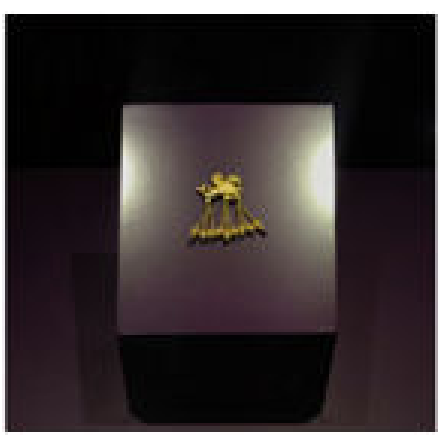

(S1k1, 2021) 
Görsel 17

Exequias Imzalı Siyah Figürlü Amfora

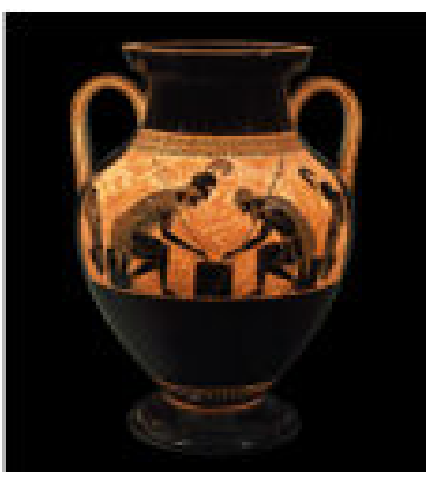

(Musei Vaticani, t.y.)

Giyilebilir form olarak el ile şekillendirilen, $1000\left({ }^{\circ} \mathrm{C}\right)$ derecede pişirimi yapılan seramikler lazer ile desenleme için taranarak sayısal ortama aktarılmıştır (Görsel 18 (a)) Lazer kabin içerisinde 1sıl işlemin gerçekleştirileceği alan belirlenmesi için şablon çalışması yapılmıştır (Görsel 18 (b)) Esin kaynağı olarak seçilen konu üzerinden desen kompozisyonları oluşturulmuştur. Seramik formların yüzeyine işlenecek desenler Adobe Photoshop ve Adobe Illustrator programları aracılığı ile geliştirilmiştir (Görsel 18 (c)) Çalışmalar $\mathrm{CO}_{2}$ gaz lazer makinasına uygun olarak Grayscale mod uzantılı olarak çalışılmış ve makinaya aktarılmak üzere Bitmap modunda kaydedilmiştir.

\section{Görsel 18}

\section{$\mathrm{CO}_{2}$ Gaz Lazer İçin Geliştirilen Çizim Çalışma Örneği}

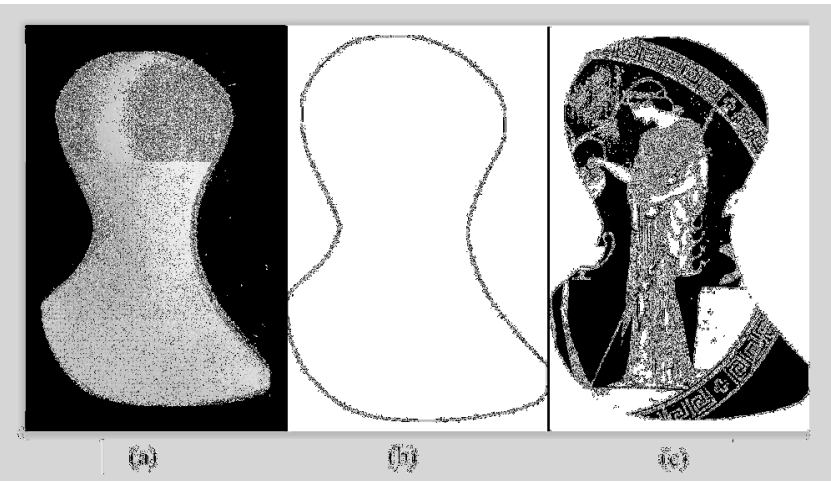

(S1k1, 2021)

Lazer ile çalışmalarda makinada kullanılan program WeldMARK 2.0.'dır. Uygulama çalışmalarında tercihe bağglı olarak 50-70 W/ mm², frekans değeri: 2-5.00 kHz değerleri arasında kullanılarak 1sıl işlem yapılmıştır. Formların üzerinde her parça için ayrı ayrı geliştirilen desen tasarımları lazer ile yüzeyde işlenmiştir. Yaratılmak istenen etkiler, teknoloji ile desteklenerek dijital ve sert görünümlü yapısı ile heykelsi bir hava katılmıştır (Görsel 19).

\section{Görsel 19}

Lazer ile Dekorlanmış Seramik Formların Görselleri

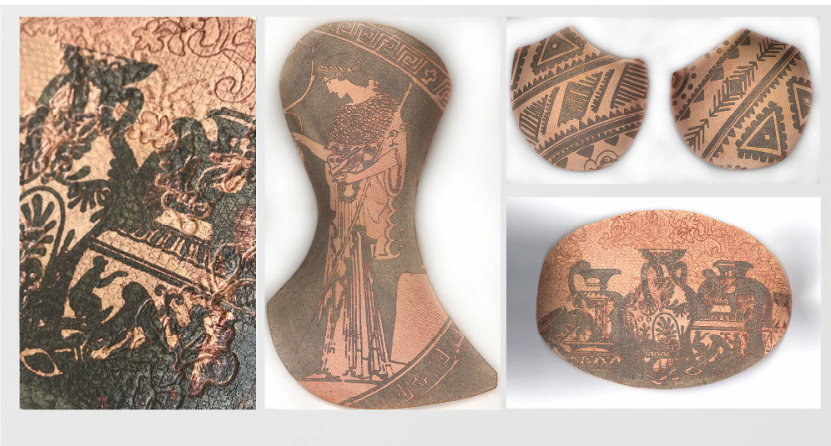

$(\mathrm{S} 1 \mathrm{k} 1,2021)$ 
Giyilebilir form olarak el ile şekillendirilen, $1000\left({ }^{\circ} \mathrm{C}\right)$ derecede pişirimi yapılan sikke formlu seramikler inkjet baskı ile desenleme için tüm yüzeye boya gelecek şekilde baskıya uygun halde yerleştirilmiştir (Görsel 20 (a)). Seramik sikke formların yüzeyine işlenecek desenler Adobe Photoshop ve Adobe Illustrator programları aracılığ ile geliştirilmiştir (Görsel 20 (b)). Baskı kafası XAAR GS12 olup ortalama 11 gram boya atan TecnoFerrari makinasında çalışmalar uygulanmıştır. Seramik formların tek yüzeyine desen işlenmiştir (Görsel 20 (c)). Duvar karosu tek pişirim bölümünde 32 dakikada $1100\left({ }^{\circ} \mathrm{C}\right)$ derece duvar karosu fırınında pişirilmiştir (Görsel 21).

\section{Görsel 20}

İnjet Baskı İçin Geliştirilen Tasarımlar, Sayısal Ortamda Geliştirilen Çizimler ve Baskı Sonrası Görselleri

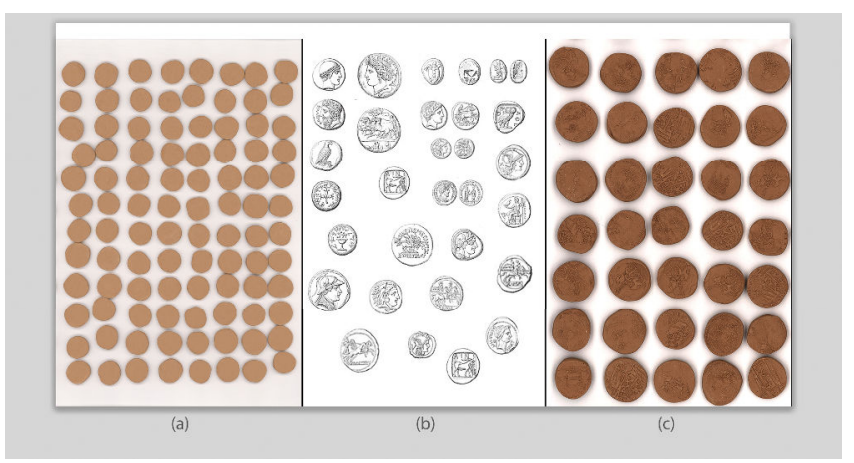

$(\mathrm{S} 1 \mathrm{k} 1,2021)$

\section{Görsel 21}

İnjet Baskı ile Desen Uygulaması Yapılmış Seramik Sikke Örnekleri
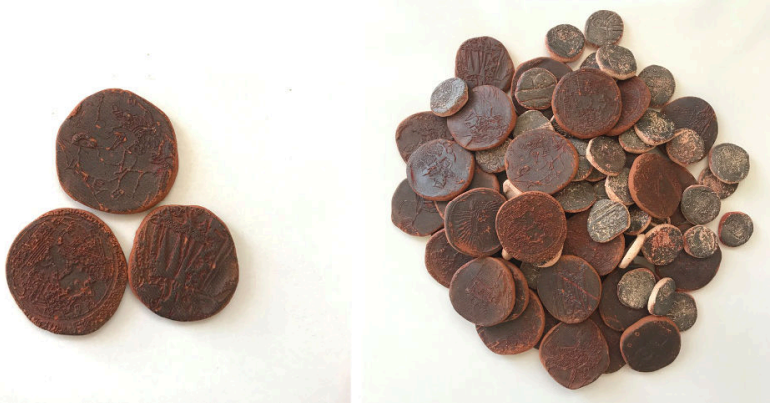

$(\mathrm{S} 1 \mathrm{k} 1,2021)$

Seramik formlar drapaj tekniği ile ortaya çıkarılan giysiler üzerine yerleştirilmiştir. Hem tekstil hem de seramik alanında kullanılan bu ortak dijital teknolojiler aracılığı ile yeni anlatım biçimi oluşturulması doğrultusunda çalışmalar geliştirilmiştir (Görsel 22, 23, 24, 25).

\section{Görsel 22}

Büstiyer ve (Amfora) Kemer Dijital Dekorasyon Teknolojisi $\mathrm{CO}_{2}$ Gaz Lazer ile Uygulama Çalışmaları
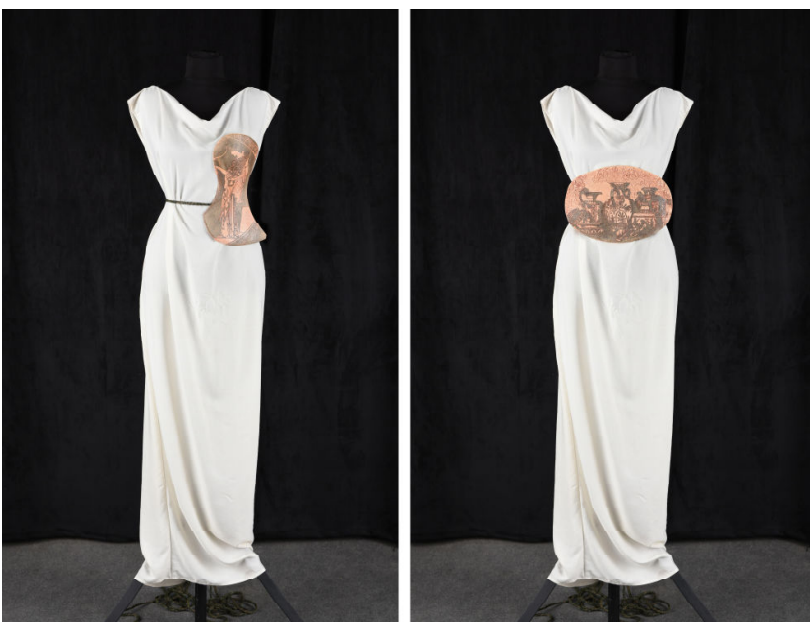

(S1k1, 2021) 


\section{Görsel 23}

Oryantel ve Işsleme Dijital Dekorasyon Teknolojisi $\mathrm{CO}_{2}$ Gaz Lazer ve Inkjet ile Uygulama Çalışmaları
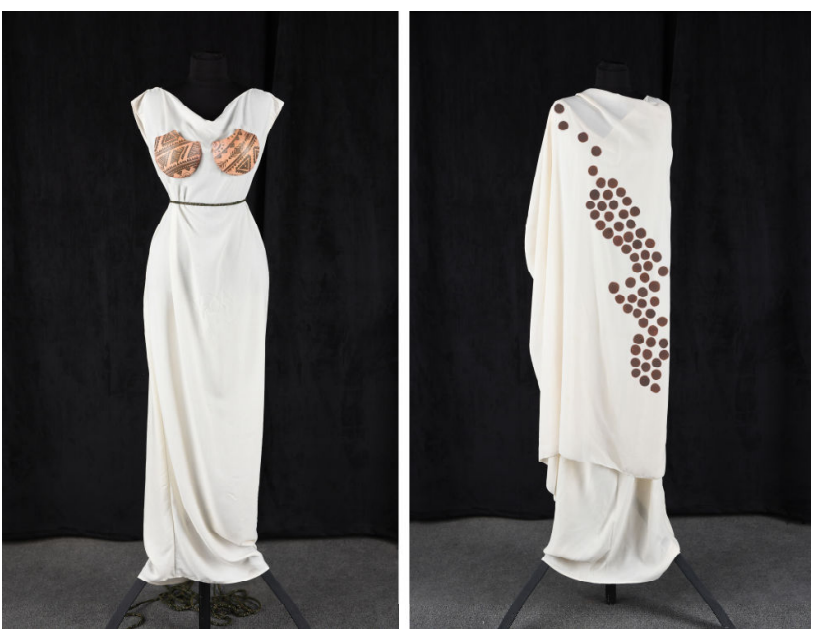

$(\mathrm{S} 1 \mathrm{k} 1,2021)$

\section{Görsel 24}

Toga ve Kanatlı Denizatı Dijital Dekorasyon Teknolojisi İnkjet ve $\mathrm{CO}_{2}$ Gaz Lazer ile Uygulama Çalışmaları
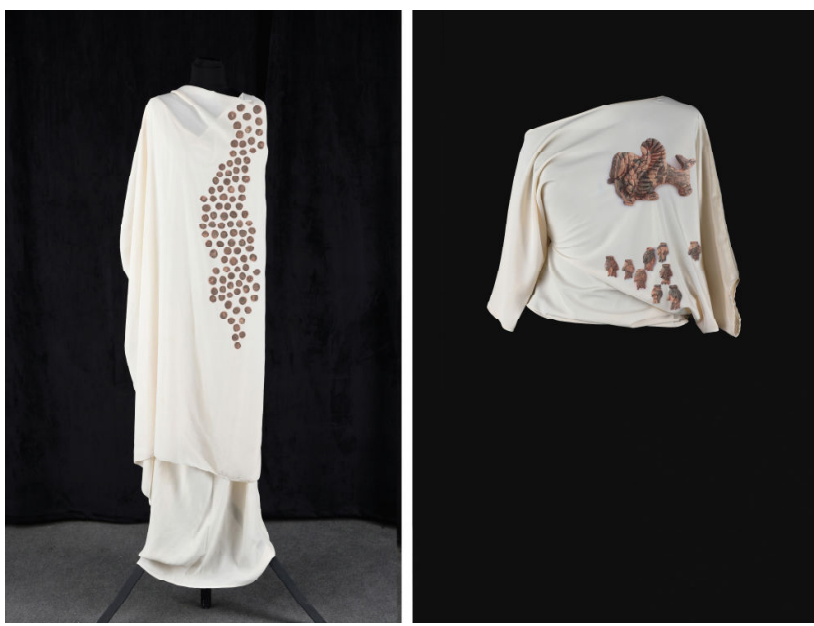

(S1k1, 2021)

\section{Görsel 25}

Serüven ve Avantür Dijital Dekorasyon Teknolojisi $\mathrm{CO}_{2}$ Gaz Lazer ile Uygulama Çalışmaları
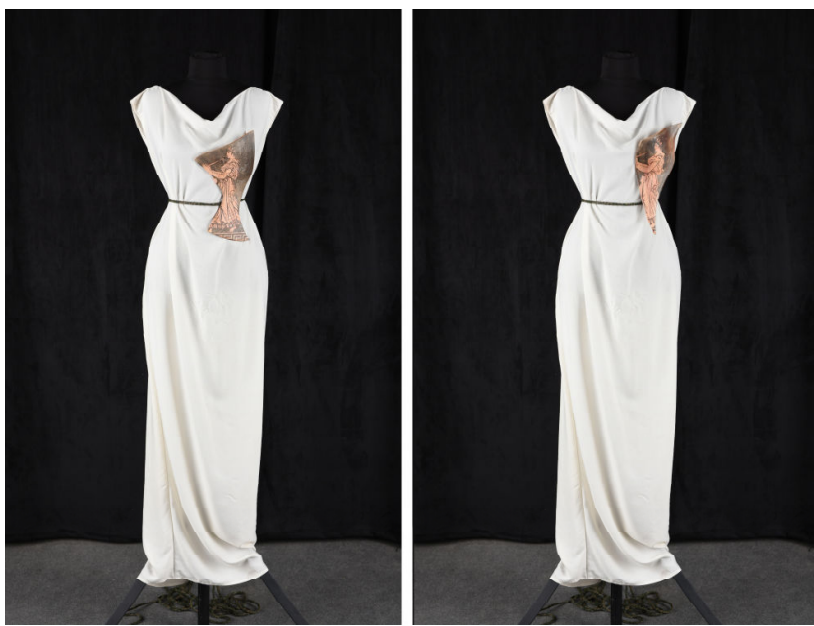

$(\mathrm{S} 1 \mathrm{k} 1,2021)$ 


\section{Sonuc}

$\mathrm{Bu}$ araştırmada Giyilebilir Sanatta Seramik Malzeme ile ilgili araştırmalar ve uygulamalar yapılmıştır. Uygulama çalışmaları, Serano Dekor Seramik Sanayi ve Ticaret Limited Şirketinde, inkjet baskı ise Hitit Seramik Sanayi ve Ticaret A.Ş.' de gerçekleştirilmiştir. Giysi, sanatçılar için kendini ifade etme biçimi olarak önemli bir unsurdur. 21. Yüzyılda hızla değişen ve gelişen teknolojik araç ve gereçler birçok farklı alanlarda kullanım bulmuştur. Bu çalışmada hem tekstil hem de seramik yüzey işleminde kullanılan dijital dekorasyon teknolojilerin tasarım geliştirme ve uygulama süreçlerine dahil edilmesi ile çalışmalara özgün değer kazandırılma amacı ile estetik ve teknik açıdan yeniden yorumlanmıştır.

Çalışmalar sonucunda, seramik malzemenin, ileri teknolojik sistemlerin sağladığı yeni yöntemler ile birçok sanat alanı ile uyum içerisinde yer edindiği gözlemlenmiştir. Porselen, düşük ve yüksek derecede pişirime uygun beyaz renkli kil vb. farklı pişirim özelliklerine sahip malzemeler ile uygulamalar yapılması planlanmış olup yeni eserler eklenerek çalışmaların geliştirilmesi hedeflenmiştir.

Dezavantaj olarak, inkjet baskı makinasının kafası belirli bir yüksekliğe kadar çıkabildiğinden 3 boyutlu yüzeylere baskılar yapılamamaktadır. Bu araştırmanın devamında sanatsal olarak bu sorunlara katkıda bulunacak ve yeni bir boyut kazandıracak araştırmalar yapılması planlanmaktadır.

Mevcut giyilebilir seramik formların ötesinde seramik endüstrisine yönelik dijital dekorasyon teknolojileri ile yorumlanarak bu teknolojilerin seramik alanında da kullanılabilirliği ile estetik ve teknik açıdan yeniden yorumlanmış olup özgün ve yenilikçi estetik değerli uygulamalar geliştirilmiştir. Yenilikçi teknolojiler olarak kabul edilen inkjet baskı yöntemleri ve lazer ile bask1, 3 boyutlu formlarda kullanımı örneği oluşturulmuştur.

Dijital dekorasyon teknolojilerin güzel sanatlar alanında kullanımına yönelik bir ders programı geliştirilerek bu teknolojiler alana entegre edilebilir. Tasarım yarışmaları düzenlenerek yenilikçi çalışmalar teşvik edilebilir.

$\mathrm{Bu}$ araştırma sonucunda; plastik sanatlar alanında teknolojinin bir araç olduğunu, sanatçının yaratım sürecinde yaratıcılığına ve özgünlüğüne yeni yollar gösterdiği, yaratıcılık alanını genişlettiği ve kolaylaştırdığı tespit edilmiştir. Günümüzde dijitalleşme ve teknolojik gelişmeler plastik sanatlarda da diğer alanlarda olduğu gibi avantajlar sağlamaktadır. Sanatçının bu avantajları kullanması yeni bakış açıları geliştirmesi dijitalleşmiş dünyada kaçınılmazdır.

Seramik sanat ve tasarım alanlarında malzemenin çeşitliği, şekillendirme ve dekorlama yöntemleri çok geniştir. Bu alanlarda kullanılmakta olan geleneksel baskı yöntemlerinden serigrafi Dekorasyon baskı, rotasyon baskı gibi çeşitli baskı sistemleri ile rölyefli yüzeylerde desenleme işlemi yapılamamasına rağmen yenilikçi teknolojiler olarak adlandırılan bu dijital dekorasyon teknolojiler ile düz yüzeylerin yanı sıra boyutlu yüzeylerde rahatlıkla desenleme yapılabilmektedir. Dijital dekorasyon teknolojileri olarak lazer ve inkjet baskı makinalarının kendi değişken parametrelerinden (örneğin baskı kafası, baskı hızı, lazer 1şın değeri) kullanıcı isteği doğrultusunda faydalanılarak görsel çeşitlilik sağlanması avantajı vardır. Bu çeşitlilik içerisinde Dijital Teknolojilerinin kullanılması ile daha detaylı ve net dokunuşların form üzerinde yapılabilmesi kolaylaşmaktadır. Bu araştırma kapsamında Dijital Dekorasyon Teknolojilerinin kullanılması eserlerin plastik değerine katkıda bulunacak dekorların daha detaylı ve net algılanmasını sağladığı ayrıca çok ayrıntılı dekorların kısa sürelerde daha etkili şekilde kullanıldığg görsel sonuçlara ulaşılmıştır.

\section{Kaynakça}

Arabalı Koşar, S. T., \& Kurtuldu, E. (2017). Giyilebilir sanatta hacim öğesi ve yeni eğilimler. 2nd International Art Symposium, Version 21 (s.25-38). Muğla, Turkey.

Arcan, A. (2011). Lazer ışını ile metallerin kesilmesine etki eden parametrelerin incelenmesi (Tez No. 318234) [Yüksek Lisans Tezi, Dokuz Eylül Üniversitesi]. Yüksek Öğretim Kurulu Tez Merkezi.

Atik, D. (2019). Giyilebilir sanat ifadesiyle moda (Tez No. 535064). [Yüksek Lisans Tezi, Ondokuz Mayıs Üniversitesi]. Yüksek Öğretim Kurulu Tez Merkezi.

Bella, V. (t.y.). Eszter imre Vivienne Bella [Ekran Görüntüsü]. Designboom._https://www.designboom.com/ readers/eszter-imre-table-wear/

Bingöl, O. (2009). Arkeoloji ve sanat tarihi: Eski Anadolu uygarlıklarl Helenistik dönemde Anadolu. T.C. Kültür ve Turizm Bakanlığı Türkiye Kültür Portalı Projesi. https://www.kulturportali.gov.tr/mrepo/eKitap/ebHelenistikDonemdeAnadolu/index.html

Boucher, F. (1987). 20,000 years of fashion the history of costume and personal adornment. Harry N. Abrams, Inc. 
Brix, S. (2019, 11 Kasim). Avustralyalı Tasarımcı Kirsten Fletcher'ın 'Woven In-tent' 2019 Supreme WOW Ikkincilik Ödülü [Ekran Görüntüsü]. ArtsHub. https://www.artshub.com.au/news-article/sponsoredcontent/grants-and-funding/sabine-brix/entries-now-open-for-2020-world-of-wearableart-awards-259178

Demiray, K. (1988). Temel Türkçe sözlük. İnkılap Yayınevi.

Dolce\&Gabbana. (t.y.). Dolce \& Gabbana Ilkbahar-Yaz 2021 Erkek Koleksiyonu [Ekran Görüntüsü]. Dolcegabbana. https://www.dolcegabbana.com/en/spring-summer-2021-mens-campaign/

Gençkaya, E. (2011). Mürekkep püskürtmeli baskı sistemlerinde solvent bazlı ve uv bazl mürekkeplerin tekstil ve branda üzerine yapılan baskılarda görüntü kalitesine etkisi (Tez No. 290351). [Yüksek Lisans Tezi, Marmara Üniversitesi]. Yüksek Öğretim Kurulu Tez Merkezi.

Geyik Değerli, N. (2019). Moda endüstrisinin giyilebilir teknoloji tasarımları. Uluslararası Bilimsel Araştırmalar Dergisi (IBAD), 4(1), 50-65. https://doi.org/10.21733/ibad.500289

Hakan Verdu Martinez, E. (2012). Moda tasarımında sanatsal ifade önerisi olarak alternatif malzemeler: Seramik $\begin{array}{lllll}\text { elbiseler. } & \text { Sanat } & \text { ve }\end{array}$ https://dergipark.org.tr/tr/pub/sanattasarim/issue/20647/ 220293

Hudd, A. (2010). Inkjet printing technologies. S. Magdassi (Ed.), The chemistry of ınkjet ınks (s. 3-18) içinde. World Scientific Publishing Co. Pte. Ltd.

Karayel Gökkaya, E. (2014). Disiplinlerarası sanatsal ifade: Ressam seramikçiler- seramikçi ressamlar. Sanat Dergisi, O(24), 25-40. https://dergipark.org.tr/tr/pub/ataunigsfd/issue/2612/33627\#article cite

Katrantzou, M. (2012). Mary Katrantzou, 2012 ilkbahar yaz koleksiyonu [Ekran Görüntüsü]. Mary Katrantzou. https://www.marykatrantzou.com/collections/spring-summer-2012/

Kodaman, L., \& Sarı, S. (2013). Disiplinlerarası bağlamda tuval resimlerinin, dijital baskı yöntemi kullanılarak giyilebilir sanatta uygulanmasına yönelik bir çalışma. Cumhuriyet International Journal of Education, 2(4), 72-83. http://dergipark.gov.tr/download/article-file/48682

Musei Vaticani. (t.y.) Anfora ática con figuras negras firmada por Exequias [Ekran Görüntüsü]. MuseiVaticani. https://www.museivaticani.va/content/museivaticani/es/collezioni/musei/museo-gregoriano-etrusco/salaxix--emiciclo-inferiore--collezione-dei-vasi--ceramica-atti/anfora-attica-a-figure-nere-firmata-daexekias.html\#\& gid=1\&pid=1

Ok, M. (2016). Giyilebilir sanat bağlamında 'Ruff Yaka'. Yedi: Sanat, Tasarım ve Bilim Dergisi, 0(16), 65-73. https://dergipark.org.tr/tr/download/article-file/228101

Özay, S. (2021). Dünden bugüne dokuma resim sanatı. Kültür ve Turizm Bakanlığı Yayınları.

Özdoğan, M. (2014). 50 soruda Arkeoloji (4. Baskı). 7 Renk Basım Yayım ve Filmcilik Şti.

Pamuk, B. (2020). Çeyiz sandığını, giyilebilir sanat ile anlatmak: Sandık sarısı koleksiyonu. OPUS-Uluslararası Toplum Araştırmalart Dergisi, 16(32), 5341-5358. https://doi.org/10.26466/opus.728845

Paret, D., \& Crégo, P. (2019). Wearables, smart textiles and smart apparel. ISTE Press Ltd. and Elsevier Ltd.

Pendaries, M. (t.y.). Marie Panderies La Dot [Ekran Görüntüsü]. Marie Pendariès Bijoux Contemporains. http://mariependaries.blogspot.com/2009/09/description-of-image-goes-here 8335.html

Sani, E. (2010, 7 Temmuz). Kırmızı figürlü kylix C. MÖ. 470 Python'a (çömlekçi) [Ekran Görüntüsü]. Flickr. https://www.flickr.com/photos/69716881@,N02/7255916688

Scott, P. (t.y.). Phoebe Scott seramik çalışması [Ekran Görüntüsü]. http://phoebe-scott-t77s.squarespace.com/ dresses/w1 eiq15tmn6qovtstzoquibpb076pf

Sıkı, C. (2021). Inkjet ve lazer baskı için uygulama çalışmaları [Fotoğraf ve Çizim]. Ceyda Sıkı Kişisel Arşivi.

Sözen, M., \& Tanyeli, U. (2012). Sanat kavram ve terimleri sözlüğü. Remzi Kitabevi.

Tarakçıŏlu, N., \& Özcan, M. (2004). Lazerler ve materyal işleme uygulamaları. Atlas Yayın Dağıtım.

Türk Dil Kurumu. (t.y.). Moda. sozluk.gov.tr içinde. https://sozluk.gov.tr/

Türk Tarih Kurumu. (1989). Eski eser tanımı ve kaçakçılı̆̆ın önlenmesi semineri notları (No. A098552A.VI/9780). T.C. Kültür Bakanlığı Kültür ve Tabiat Varlıklarını Koruma Başkanlığı. https://kutuphane.ttk.gov.tr/details?id= 562433\&materialType $=\mathrm{KT} \& q u e r y=\mathrm{K} \% \mathrm{C} 3 \% \mathrm{BClt} \% \mathrm{C} 3 \% \mathrm{BCr}+\mathrm{varl}$ $\% \mathrm{C} 4 \% \mathrm{~B} 1 \mathrm{klar} \% \mathrm{C} 4 \% \mathrm{~B} 1+$ +Koruma $++\mathrm{T} \% \mathrm{C} 3 \% \mathrm{BCrkiye}$ 
Van der Molen, M. (t.y.). Malou van der Molen seramik elbise çalışması [Ekran Görüntüsü]. Malouvandermolen. https://malouvandermolen.com/grenswachter-in-het-tussenruim.html

Xiaofeng, L. (t.y.). Li Xiaofeng Porselen Malzeme ile Kostüm [Ekran Görüntüsü]. Red Gate Gallery. https://www.redgategallery.com/content/li-xiaofeng

Yeşilmen, N. (2018). Giyilebilir sanat örneği olarak 21. yüzyılda seramik takılar. Ídil Dergisi, 7(50), 1251-1255. https://doi.org/10.7816/idil-07-50-06 